\title{
Influence Functions of Shell Deflection in Soil-Steel
}

\section{Bridges}

\author{
Czeslaw Machelski ${ }^{1}$, Leszek Janusz ${ }^{2}$ and Adam Czerepak ${ }^{2}$ \\ 1. Bridge and Railway Department, Faculty of Civil Engineering, Wroclaw University of Technology, Wroclaw 50-370, Poland \\ 2. ViaCon Company, Rydzyna 64-130, Poland
}

\begin{abstract}
This paper analyze the effects of loads changing position on the soil-steel structures made of corrugated plates. The analyzed quantity is the shell deflection depending on the location of vehicles. On this basis, the influence functions of deflection are determined. On the basis of results of tests conducted on numerous soil-steel structures, it has been proved that the deflection influence line, which is commonly used in the static analysis of bridges, can not be obtained for this type of structures. This is due to the form of deflection and deflection differences that occur during a primary passage and a secondary (return) passage of the moving load. The deflection influence functions analyzed in the paper are used to determine the stiffness of classic beam bridges, masonry bridges and soil-steel structures. This allows to conduct comparative analyses of different groups of bridges (road bridges, railway bridges, pedestrian bridges), using results of the tests performed under the service load.
\end{abstract}

Key words: Soil-steel bridges, corrugated steel, deflection of bridge.

\section{Introduction}

Acceptance tests are performed on built structures in order to assess the quality of construction works. In such tests, static stationary loads (placed on the roadway of the structure) - vehicles are most often used to obtain maximum values of forces or displacements that are provided in the design of the structure. At times, the mentioned load has the properties of a long-term load, as it occurs until a stable measurements can be recorded. In the case of important and prototypical structures, dynamic tests are also performed. In such cases, the service load is used [1]. In road bridges, the load is reduced to a single vehicle, and sometimes, to a group of two cars moving at different speeds. Similar tests are performed on structures that have been used for a long time, in order to check their condition. In this case, the range of tests is adapted to the criterion of assessment of the performance of the structure [2].

Corresponding author: Adam Czerepak, M.Sc., export manager, research fields: civil engineering, road and railway infrastructure.
In some cases, bridge structures are tested under loads that change their location, but act in a quasi-static manner [3]. The passage of such load allows for determining the deflection function, which is characteristic of bridge structures. The example of tests performed on the built structure under actual construction load is given below. The structure was built solely for the purpose of cognitive analyses [3]. It was constructed from a drop-shaped (box-shape) shell with geometrical parameters $L=6.04 \mathrm{~m}$ and $h=4.55 \mathrm{~m}$, made from corrugated sheet MP $200 \times 55 \times 2.93$ type. The wheel (axle) load of the loader with a full bucket, as shown in Fig. 1a, was $2 P=221 \mathrm{kN}$.

In this case, the analysis concerned the structure without a surface, but with different soil levels (backfill thickness above the shell crown). The result of the measurements was the diagram illustrating shell crown deflection $w(x)$ versus position of the moving loader, as shown in Fig. 1b. The graph presented in Fig. $1 \mathrm{~b}$ refers to the case of the soil backfill thickness of $1.50 \mathrm{~m}$ above the crown, that is, when $z_{g}=6.05 \mathrm{~m}$. When $x=0$, the front axle of the loader is located above the shell crown, and when $x=3.4 \mathrm{~m}$, the second 
axle is located in this area. The passage usually leaves residual displacements. In this case, residual displacements of $0.13 \mathrm{~mm}$ were observed.

Tests of bridges under a service load that changes its location can also be performed. This can be seen in the example given in Fig. 2a. In this case, the tested structure was built in 1875 . It was a masonry barrel vault with a thickness of $0.80 \mathrm{~m} \mathrm{[2].} \mathrm{The} \mathrm{width} \mathrm{of} \mathrm{the}$ single-track railway structure was $8.55 \mathrm{~m}$. Fig. $2 \mathrm{~b}$ presents one of the results of measurements conducted under the load consisting of the ET22 locomotive with wagons. The train was moving with a small speed of $v=10 \mathrm{~m} / \mathrm{s}$, so the load was acting almost static. On the diagram showing deflection $w(t)$, the influence of moving wagons is visible, but as they were not loaded, the deflection has small values. The comparison of deflection of both structure types shows a significant disproportion in the stiffness between the soil-steel structure made of corrugated plates and the brick barrel vault $[4,5]$.

\section{Analyzed Corrugated Sheet Structure}

The paper presents the test results of a structure located in Świdnica. It is a soil-steel structure made of SuperCor corrugated sheets of type SC $380 \times 140 \times 7$ (length of the wave, height of the wave, thickness of the sheet $(\mathrm{mm}))$, with full sheet overlay of SC $380 \times$ $140 \times 5.5$ type. The geometry of the circumferential band of the shell was a typical arch-shaped profile marked as SC-19NA, with dimensions specified in Table 1. A characteristic feature of the soil-steel structures is a substantial influence of the soil backfill and the surface as load-bearing elements. Hence, it is necessary to note the importance of $h_{k}$ dimension, given in Table 1. The results of the tests were compared with the structure of a different geometry, built

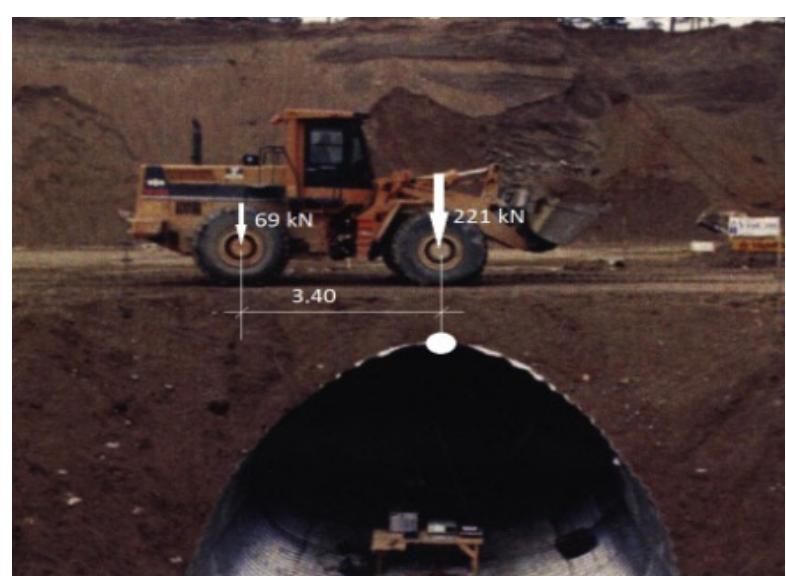

(a)

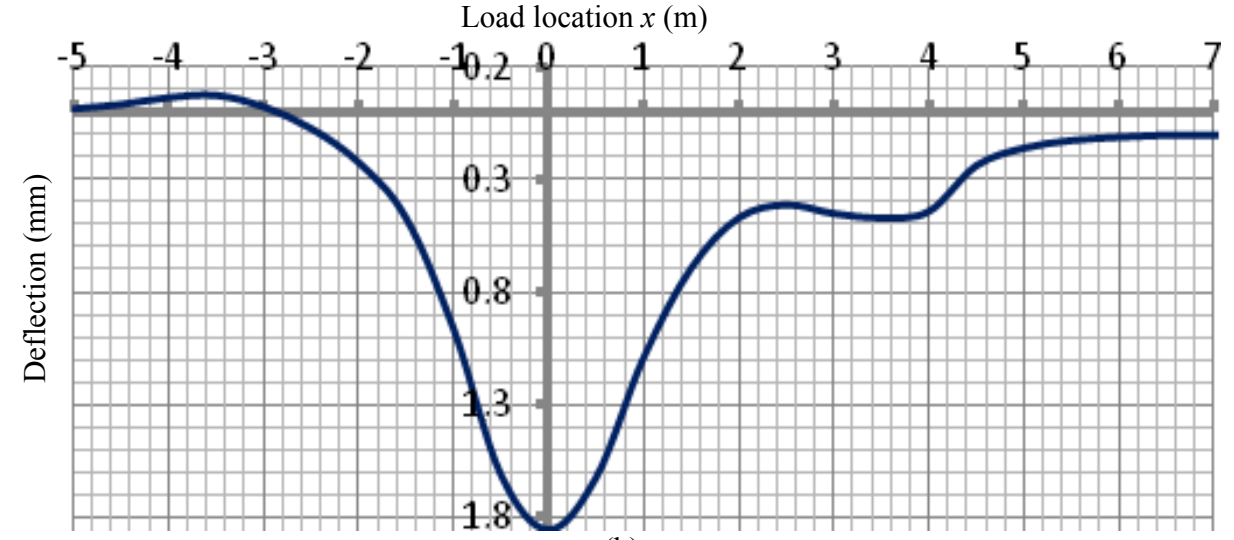

(b)

Fig. 1 Crown deflection in a corrugated sheet shell structure during passing of the loader: (a) result of the wheel (axle) load; (b) result of the measurements [3]. 


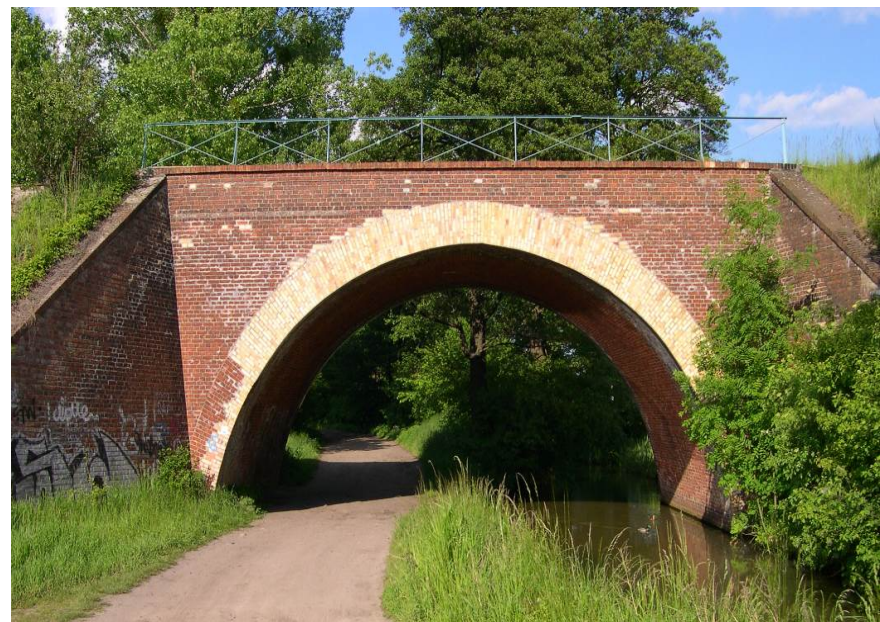

(a)

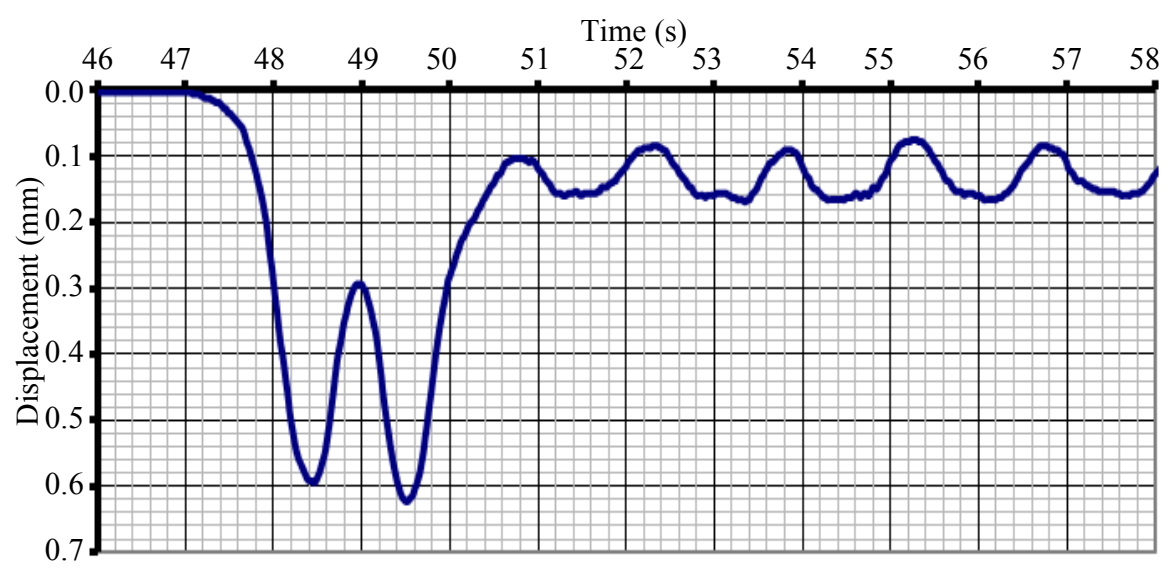

(b)

Fig. 2 Deflection in the crown of the masonry vault during passing of the train: (a) the example; (b) one of the results of measurements [2].

Table 1 Geometrical characteristics of tested structures.

\begin{tabular}{|c|c|c|c|c|}
\hline \multirow{2}{*}{ Structure } & \multicolumn{3}{|c|}{ Geometry of the shell } & \multirow{2}{*}{-Height of backfill over the crown $h_{k}(\mathrm{~m})$} \\
\hline & $L(\mathrm{~m})$ & $h(\mathrm{~m})$ & $R(\mathrm{~m})$ & \\
\hline Prabuty & 7.945 & 2.370 & 8.820 & 1.20 \\
\hline Świdnica & 15.00 & 5.232 & 9.930 & 1.60 \\
\hline Milicz & 12.80 & 6.400 & 6.400 & - \\
\hline
\end{tabular}

in Prabuty. Despite a significant difference in geometrical characteristics of these structures, similar results were obtained [4].

Locomotives are the main load for short-span railway bridges, as analyzed in this paper. Table 2 summarizes geometrical parameters and axle loads of the locomotives used in the tests. Distance of the trucks (bogies) is a characteristic dimension of six-axle locomotives (just as the values of spacing of single axles $a$ and $c$ ), which equals $d=2 a+c$, as shown in Table 2. A characteristic feature of each locomotive is the same axle load $P$, which has a similar value in all types of locomotives. Therefore, it is possible to compare the results of the measurements.

\section{Method of Testing Deflection Function in Railway Bridges}

The testing methodology used for the analyzed structures adopts the measurement of deflection during the passage of the locomotive along the longitudinal axis of the structure. The location of the 
Table 2 Technical parameters of locomotives.

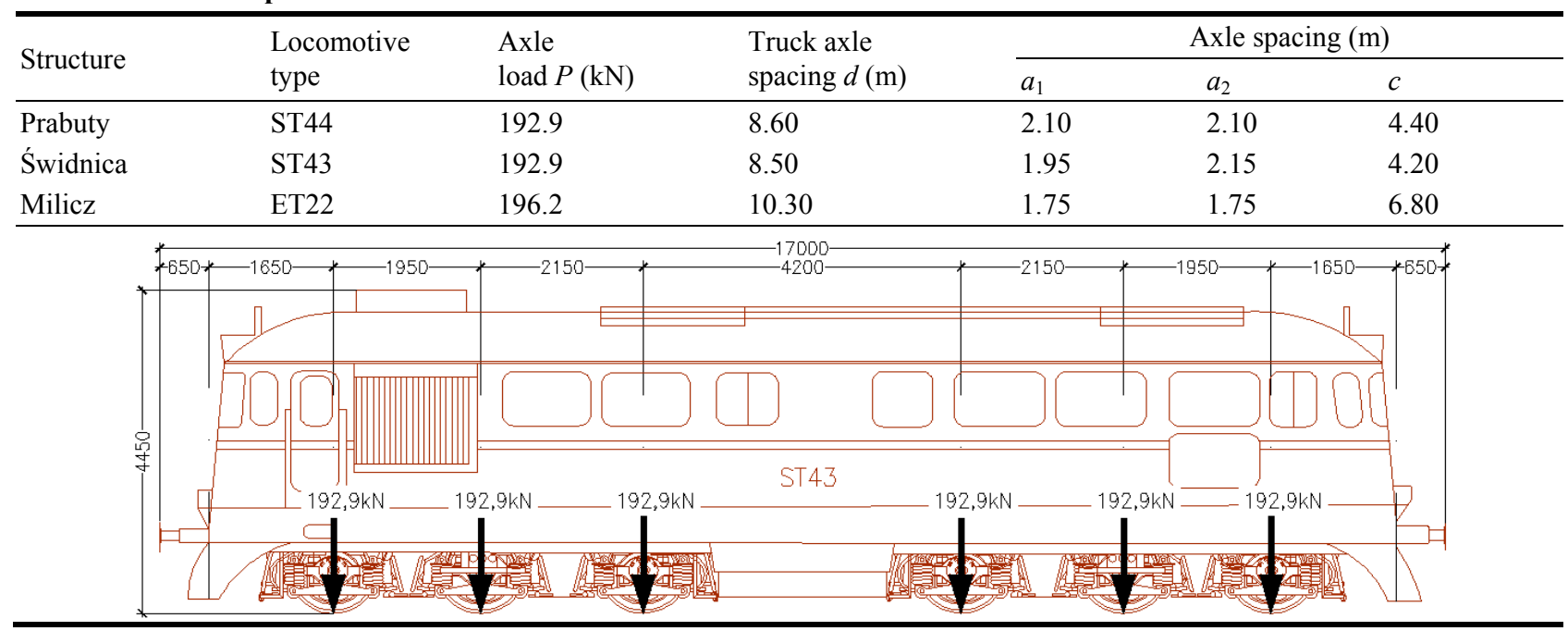

vehicle on the structure is determined by $x$ coordinate (m), which stands for the distance from the crown to the central axle of the truck (the reference axle of the vehicle). Therefore, when $x=0$, the central force in the truck is located above the crown, and the two remaining forces are located at the distance $a$ on the left and on the right side of the crown. When $x=d / 2$, the locomotive takes a symmetrical location on the structure. At this point, both trucks of the locomotive are equally distant from the axis of symmetry of the structure.

Figs. 2 and 3 present the diagrams of crown deflection during the passage of the locomotive over the analyzed structures. Comparison of the diagrams indicates their similarity, despite significant differences in structural configuration and geometry of the structures. From the form of the functions $w(t)$ and $w(x)$, the moment of the first and the second entrance of the locomotive truck on the structure is visible. The distance of the extreme values is close to $d$ value given in Table 2. The graphs in Fig. 3 show no evident contribution of the individual truck axles, which results from the distribution of the forces $P$ by the railroad surface and the bridge structure. In the case of soil-steel structures, values $w(x)<0$ are observed before the locomotive appears over the structure. In the case of the masonry arch bridge, only deflections $w>0$ in the entire range $t$ are observed. After passing of the locomotive, residual displacements of different values can be observed $[2,3,6,8]$.

\section{Influence Functions of Shell Deflection}

The testing methodology used for the analyzed structures (Fig. 4) adopts the measurement of shell deflection during passing of a locomotive along the track. The location of the locomotive on the structure is determined by $x$ coordinate, which stands for the distance from the crown to the central axle of the truck (the leading axle of the vehicle). On the basis of the diagram $w(x)$ (Fig. 1b) or $w(t)$ (Fig. 2b), it is possible to draw a diagram of the influence function of deflection $\eta(x)$ (Figs. 5 and 6), in these cases in the crown section. For this purpose, identical locomotive axle loads $P$, as specified in Table 2, are applied. In accordance with these assumptions, a general dependence between deflection and the ordinates of the influence function of deflection under concentrated forces $P$ is obtained in Eq. (1):

$$
w(x)=P \sum_{i=1}^{n} \eta\left(x_{i}\right)
$$

where, $x$ is the location of the leading axle of the locomotive, and $x_{i}$ is the location of the axles of the vehicle (forces $P$ ). 


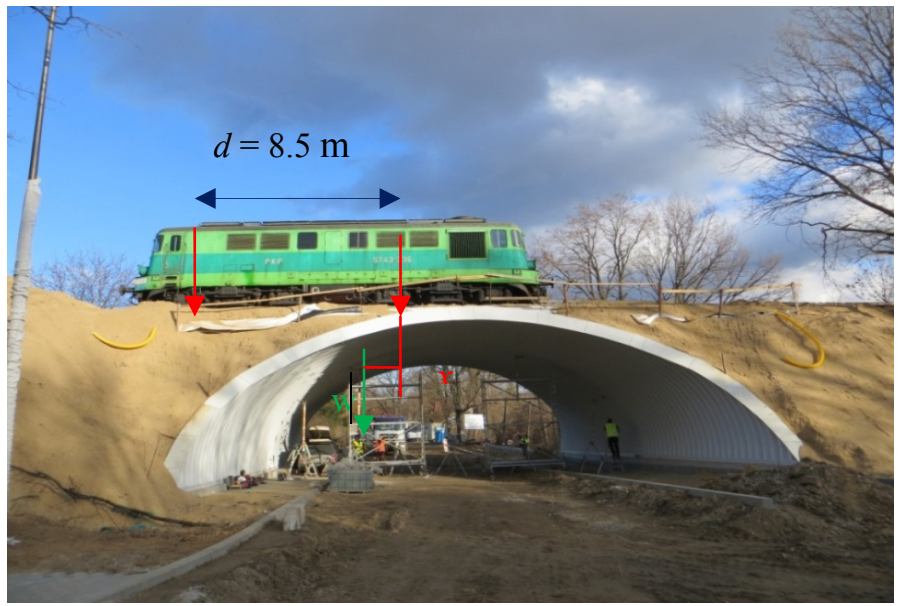

(a)

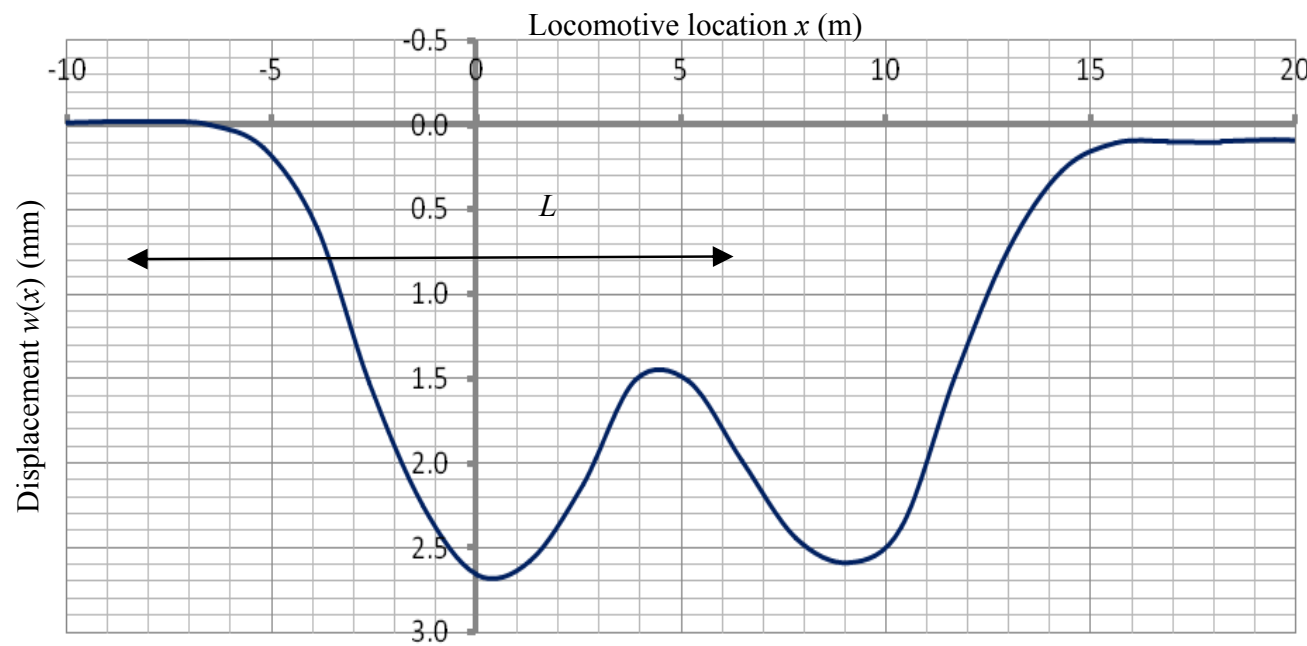

(b)

Fig. 3 Crown deflection in a corrugated sheet shell structure during ST43 locomotive loader: (a) direction of movement; (b): the result.

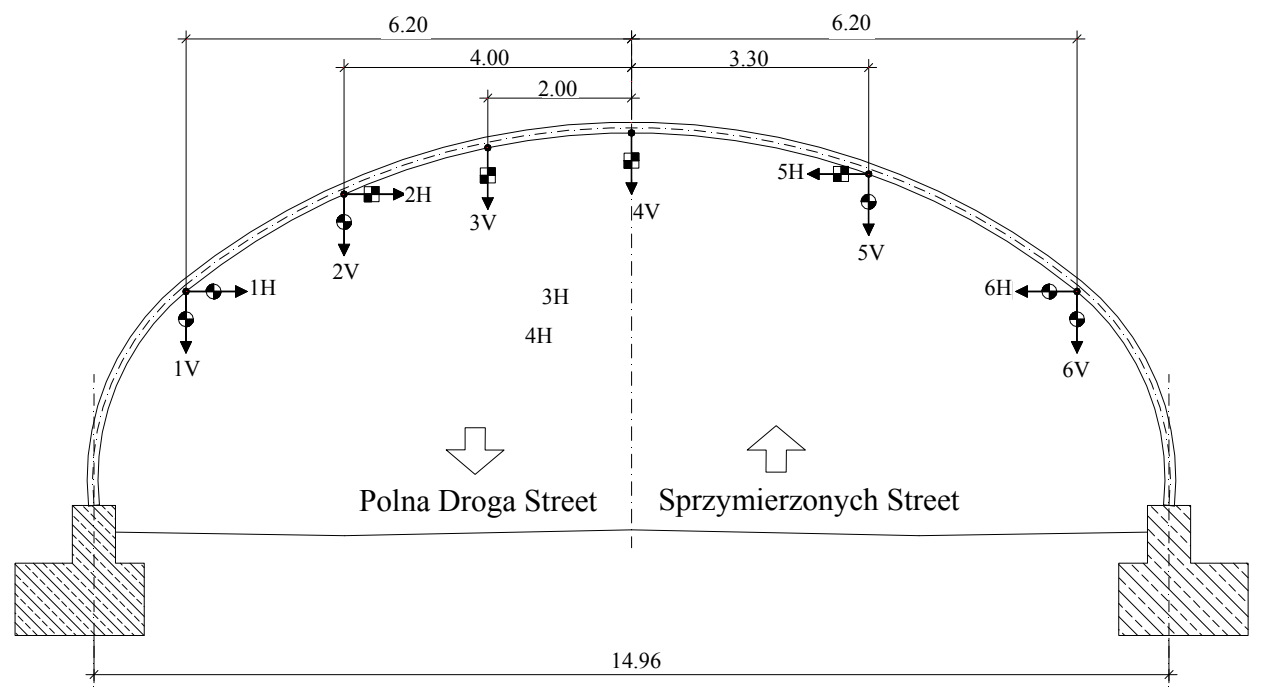

Fig. 4 Location of the measurement points on the shell. 


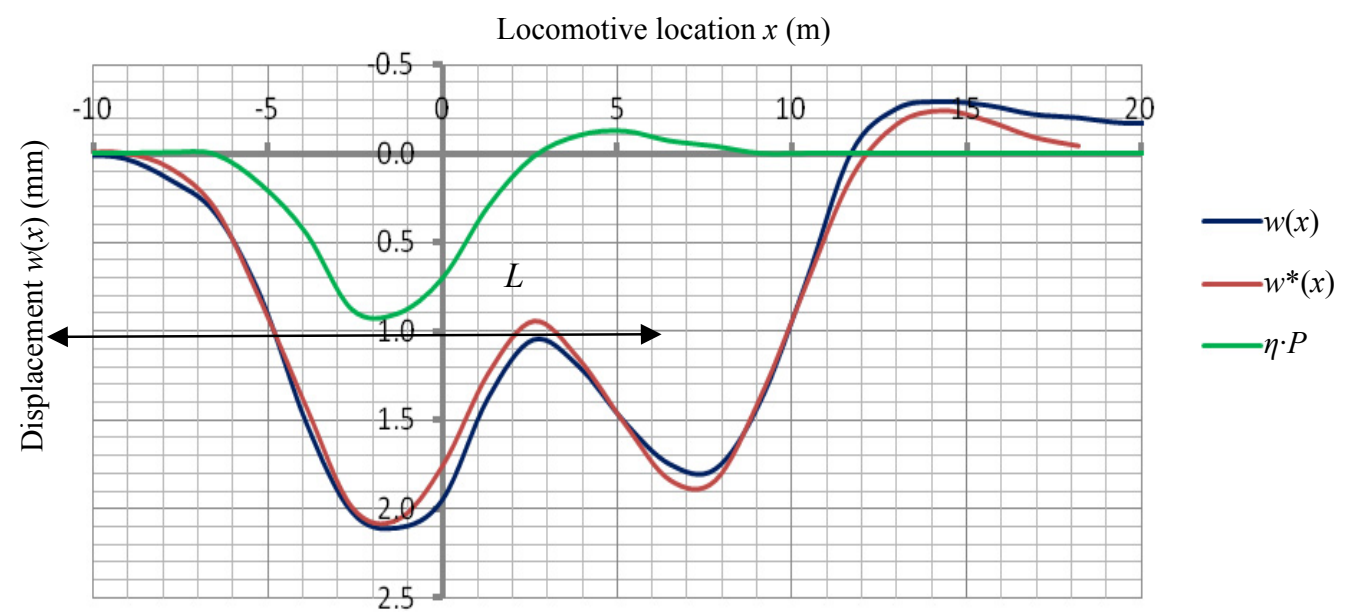

Fig. 5 Change in the deflection of Point 3 of the shell in the structure in Świdnica.

In order to determine the ordinates of the influence function $\eta\left(x_{i}\right)$, a step-by-step procedure is used. The procedure starts with the point $x=x_{0}$, in which deflection $w\left(x_{0}\right)$ occurred, when in the preceding point (and also in the previous points) the deflection was $w\left(x_{0}-a\right)=0$. Thus, the calculations use the initial location of the first force $P$ (the axle of the locomotive) and the dependence:

$$
w\left(x_{0}\right)=P \cdot \eta\left(x_{0}+a\right)
$$

From Eq. (2), $\eta\left(x_{0}+a\right)$ is calculated, when, by assumption, $\eta\left(x_{0}\right)=0$. The second ordinate of the influence function is calculated when the considered point is distant from the previous point by value $a$, hence the Eq. (3) is used:

$$
w\left(x_{0}+a\right)=P \cdot \eta\left(x_{0}+a\right)+P \cdot \eta\left(x_{0}+2 a\right)
$$

If the third axle of the locomotive truck enters the active zone, the following Eq. (4) is obtained:

$$
\begin{aligned}
& w\left(x_{0}+2 a\right)=P \cdot \eta\left(x_{0}+a\right)+ \\
& P \cdot \eta\left(x_{0}+2 a\right)+P \cdot \eta\left(x_{0}+3 a\right)
\end{aligned}
$$

On the basis of Eq. (4), $\eta\left(x_{0}+3 a\right)$ is calculated, since $\eta\left(x_{0}+a\right)$ and $\eta\left(x_{0}+2 a\right)$ have been already determined with the use of the previous Eq. (1). Further calculations involving the change in the locomotive location and an increase in the value of $x=x_{0}+i \cdot a$ allow for determining subsequent ordinates of the deflection influence function, as shown in Fig. 5. Deflection graph and the deflection influence function graph (Fig. 5) refer to the span of the structure $L$. In order to present the diagram $w(x)$ together with the diagram $\eta(x)$, the latter was multiplied by the value $P$. Fig. 5 presents the diagram illustrating the deflection of the Point 3 , obtained from the measurements, that is $w(x)$, the influence function of deflection $P \cdot \eta(x)$ and the function calculated from Eq. (1) marked as $w^{*}(x)$, which is consistent with the results of the measurements $w(x)$.

The ordinates of the deflection influence function can be positive or negative in corrugated sheet structures. In the case of masonry arched structure, the ordinates are only positive, as shown in Fig. 2. However, all diagrams have similar shape, which allows for common analyses of these arched-shaped structures [4].

\section{Dependence between Deflection Influence Line and Deflection Influence Function}

If a single concentrated force $P$ (with a unit value) changes its location along a straight line, as in the case of railway bridges, the deflection diagram is the influence line, as presented in Figs. 5 and 6. However, from the definition of the deflection influence line $\eta(x)$ it follows, this line does not depend on the type of the load (e.g., a group of concentrated forces) and the 

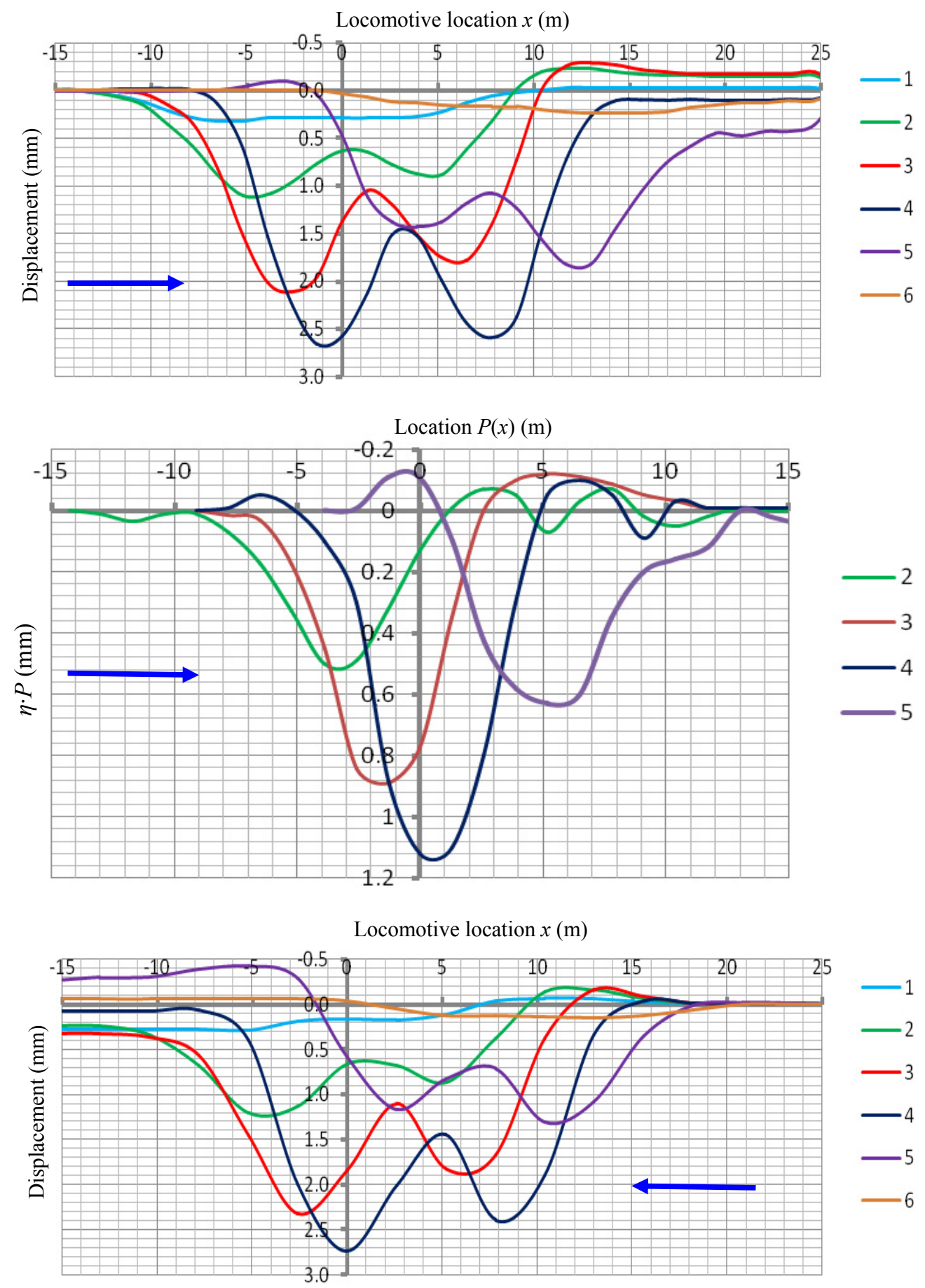

Fig. 6 Influence functions $\eta(x)$ in the measurement points of the shell, as shown in Fig. 4.

direction of the vehicle's movement along the designated path. Thus, the influence line is a constant feature of the analyzed value (force, displacement).

Multiple tests of soil-steel structures made of corrugated sheets demonstrate that the direction of movement of a vehicle and repetitiveness of the (primary) passage and the (secondary) return passage have a significant influence on the analyzed quantity [6, 7]. Therefore, the results of deflection measurements and, hence, the calculated values $\eta(x)$, 
constitute the influence functions for these structures, as shown in the paper. Grounds for the conclusion, presented on the example of the analyzed structure, are given below. The results of the measurements concern four points of the shell located along the axis of the track, as shown in Fig. 4.

Fig. 6 presents of deflection and deflection influence functions in the analyzed points of the shell, created during the primary and the secondary passage. The direction of movement of the ST43 locomotive on the structure shown in Fig. 3a is marked with arrows. The passage started when $x<0$, and ended on the other side of the structure, when $x>0$. Subsequently, the return passage along the same track and in the same configuration (the same layout of the locomotive axles) was conducted. Therefore, the identical distribution of the locomotive load was observed at identical $x$ coordinates. This makes it possible to compare the graphs (Fig. 6) of the influence function $\eta(x)$, composed from $w(x)$, created during the primary and the secondary passage. The form of Fig. 6 suggests that these functions are different, however, they have the following common features:

- In the case of the shell crown section, the extreme does not depend on direction of the passage, however, there are differences in the shapes of the diagrams;

- In the case of intermediate points, the occurrence of the extreme is delayed in relation to the location of the analyzed point;

- The maximum deflection values occur during the secondary passage.

\section{Conclusions}

The function of deflection in bridges is a diagram of displacements of the analyzed point as the load travels along the vehicle's motion path. The procedure for testing the structure and calculating the deflection influence function on the basis of the tests, which is proposed in the paper, constitutes the basis for determining the stiffness of the structure. The procedure can constitute an effective measure for assessment of the quality of construction works for the soil-steel structures. It can also be used to control the condition of masonry and concrete vault structures that have been exploited for many years, as indicated in the paper. The stiffness of a structure $[4,5]$ is a general characteristic of different structural systems (e.g., concrete and steel systems) and static schemes (e.g., suspended structures, frames, trusses), which have an intended functional purpose (e.g., road bridges, pedestrian bridges). The stiffness of a structure can also be determined in dynamic tests of bridges $[1,4,5]$.

On the basis of results of tests conducted on numerous soil-steel structures made of corrugated sheets, it has been determined that the deflection influence line, which is commonly applied in the calculations of bridges, can not be obtained for this type of structures. This is due to the form of deflection and deflection differences that occur during the primary passage and the return passage of moving loads, as indicated in the paper. In the soil-steel structures made of corrugated sheets, these functions are similar to the ones obtained for masonry bridges, which allows for a common analysis of these arch-shaped structures [4]. According to the classic division of bridges, stiff and flexible structures can be distinguished. The comparison of deflections in soil-steel structures and masonry bridges, as shown in the paper, demonstrates that each of these structures belongs to a different group.

Due to their characteristics, soil-steel structures and arch vault structures are advantageous as railway structures, since the foundation for the rail track is similar along the whole route. There is no "step" effect typical for classic bridges with abutments.

\section{References}

[1] Mellak, P., Anderson, A., Pettersson, L., and Karomi, R. 2014. "Dynamic Behaviour of Short Span Soil-Steel Composite Bridge for High-Speed Railways-Field Measurements and FE-Analysis." Engineering Structures 69 (6): 49-61. 
[2] Kamiński, T., and Bień, J. 2015. "Condition Assessment of Masonry Bridges in Poland." In Proceedings of 2015 Conf. Concepcao, Conservacao e Reabilitacao de Ponts, 126-35.

[3] Pettersson, L. 2007. "Full Scale Tests and Structural Evaluation of Soil Steel Flexible Culverts with Low Height of Cover." Doctoral thesis, Royal Institute of Technology.

[4] Machelski, C., Czerepak, A., and Bogdan, M. 2015. "Comparison of Stiffness of Railway Classic Bridges with Soil-Steel Flexible Structures Bridges." In
Proceedings of 3th B\&H Congress on Railways, 115-21.

[5] Machelski, C. 2015. "Stiffness of Railway Soil-Steel Structure.” Studia Geotechnika et Mechanica 4: 29-36.

[6] Machelski, C., and Janusz, L. 2015. "The Effects of Positioning Live Loads over Flexible Soil-Steel Structures." In Proceedings of 94th Annual Meeting Transportation Research Board, 15-3359.

[7] Machelski, C., and Toczkiewicz, R. 2012. "Identification of Connection Flexibility Effects Based on Load Testing of a Steel-Concrete Bridge." Journal of the Civil Engineering and Architecture 11: 1504-13. 